\title{
Maternal Vitamin D Levels and Its Correlation With Low Birth Weight in Neonates: A Tertiary Care Hospital Experience in Saudi Arabia
}

Eyad Almidani ${ }^{1}$, Abdullatif Barkoumi ${ }^{2}$, Weam Elsaidawi ${ }^{1}$, Saleh Al Aliyan ${ }^{1}$, Abdulhakiem Kattan ${ }^{1}$, Fahad Alhazzani ${ }^{1}$, Mohammed bin Jabr ${ }^{1}$, Abdulaziz Binmanee ${ }^{1}$, Nada Alsahan ${ }^{3}$, Saria Alazmeh ${ }^{4}$

1. Pediatrics, King Faisal Specialist Hospital and Research Centre, Riyadh, SAU 2. Pediatrics, Alfaisal University College of Medicine, Riyadh, SAU 3. Obstetrics and Gynaecology, King Faisal Specialist Hospital and Research Centre, Riyadh, SAU 4. Medicine, Alfaisal University College of Medicine, Riyadh, SAU

Corresponding author: Eyad Almidani, emidani@kfshrc.edu.sa

\section{Abstract \\ Introduction}

A meta-analysis showed that $63.6 \%$ of the Saudi population have vitamin D deficiency, including many pregnant women. Studies showed that maternal vitamin D deficiency during pregnancy is a risk factor for low birth weight (LBW) in neonates. Neonatal LBW is a risk factor for multiple neonatal complications including respiratory distress syndrome, necrotizing enterocolitis, chronic renal disorders, seizures, and sepsis. Our objective in this study is to determine a correlation between low maternal vitamin D level and neonatal LBW in Saudi Arabia.

\section{Methods}

Neonates $(\mathrm{n}=119)$ were divided based on their gestational age (GA) into full-term neonates $(\geqslant 37$ weeks) and preterm neonates ( $<37$ weeks) and based on birth weight into normal birth weight neonates (full-term $=$ 2,500-3,500 g or preterm $>10$ th percentile) and LBW neonates (full-term $<2,500 \mathrm{~g}$ or preterm $<10$ th percentile). Vitamin D deficiency is defined as 25 - hydroxyvitamin D level less than $50 \mathrm{nmol} / \mathrm{L}$.

\section{Results}

Correlating neonatal birth weight with maternal vitamin D level during pregnancy was statistically insignificant for both full-term neonates and preterm neonates. In contrast, comparing the mean maternal vitamin D levels in each neonatal group showed that the mean were higher in mothers of neonates with normal birth weight.

\section{Conclusion}

Because $87.4 \%$ of mothers had low vitamin D levels during their pregnancy, correlation between maternal vitamin D level and LBW in neonates could not be found. However, mean maternal vitamin D levels were higher in mothers with normal birth weight neonates. Therefore, further detailed studies are required to

Review began 04/06/2021 Review ended 04/13/2021 Published 04/16/2021

๑) Copyright 2021 Almidani et al. This is an open access article distributed under the terms of the Creative Commons Attribution License CC-BY 4.0., which permits unrestricted use, distribution, and reproduction in any medium, provided the original author and source are credited.
Categories: Obstetrics/Gynecology, Pediatrics, Public Health

Keywords: low birth weight, saudi arabia, vitamin d, birth weight, pediatrics \& neonatology, public awareness of vitamin d, term neonates, preterm neonate, neonatal intensive care unit (nicu), maternal-child health

\section{Introduction}

Vitamin D is a fat-soluble vitamin produced in the body through the interaction of sunlight with 7dehydrocholesterol (chemical precursor for vitamin D); the UV light breaks one of its chemical bonds to convert it into the active vitamin. Vitamin D is found in two forms: vitamin D3 (cholecalciferol) in humans and animals and vitamin D2 (ergocalciferol) in plants [1,2]. Vitamin D has a key role in bone mineralization by interacting with calcium and parathyroid hormone homeostasis [3].

Vitamin D concentration in the body depends on multiple factors such as by geographic location, latitude, skin pigmentation, and seasonal changes (in countries with a long winter season, vitamin D deficiency is very common especially among pregnant women). Also, nearly half of African-American pregnant women in the United States have vitamin D deficiency (vitamin D level less than $37.5 \mathrm{nmol} / \mathrm{L}$ ), while it is less than $30 \%$ in Caucasian women. Concentration of $25(\mathrm{OH}) \mathrm{D}$ in maternal circulation correlate with those found in the placental veins, which means that calcidiol easily passes through the placental barrier and the fetal vitamin D level depends mainly on the maternal vitamin D. In countries where the milk products are not supplemented with vitamin D, the dual-energy X-ray absorptiometry (DEXA) of the infants shows lower whole-body mineral value compared to infants in countries with supplemented milk products [4]. 
In a country like Saudi Arabia known for its sunny climate, you would expect most of the population to have sufficient levels of vitamin D, but a meta-analysis showed that $63.6 \%$ of the Saudi population have vitamin D deficiency, including many pregnant women. This could be related to multiple reasons such as inactivity of the community, diabetes mellitus, and obesity [5].

Studies recently showed that maternal vitamin D deficiency during pregnancy is a risk factor for low birth weight (LBW) in neonates [3,5]. In Saudi Arabia, 7.4\% of the neonates are born with LBW (excluding stillbirths) [6], and their mortality rate is 40 times higher than normal birth weight neonates [3]. Neonatal LBW is a strong risk factor for multiple long-term and short-term neonatal complications including respiratory distress syndrome, necrotizing enterocolitis, chronic renal disorders, seizures, anemia, sepsis, and attention deficit hyperactivity disorder (ADHD) [7,8]. Also, it is a risk factor for multiple maternal disorders such as preeclampsia, insulin resistance and gestational diabetes mellitus, and higher risk of primary cesarean delivery [4].

Our objective in this study is to determine a correlation between low maternal vitamin $\mathrm{D}$ level and neonatal LBW in Saudi Arabia.

\section{Materials And Methods}

This is a retrospective cohort study including neonates born between November 2016 and October 2018 at King Faisal Specialist Hospital and Research Center (KFSH\&RC), Riyadh, Saudi Arabia. Neonates were divided based on their gestational age into full-term neonates ( $\geqslant 37$ weeks Gestational Age) and preterm neonates ( $<37$ weeks' gestational age). Also, neonates were divided based on their birth weight into normal birth weight neonates (full-term between 2,500-3,500 $\mathrm{g}$ or preterm > 10th percentile) and LBW neonates (full-term $<2,500 \mathrm{~g}$ or preterm $<10$ th percentile of the population) $[6,9]$. Then, maternal vitamin D level was correlated with neonatal birth weight and compared between all groups.

Vitamin D deficiency is defined as vitamin D level less than $50 \mathrm{nmol} / \mathrm{L}(20 \mathrm{ng} / \mathrm{mL})$ of 25 -hydroxyvitamin $\mathrm{D}$, 25(OH)D, and insufficiency level is between 51 and $74 \mathrm{nmol} / \mathrm{L}(21-29 \mathrm{ng} / \mathrm{mL})[5]$. The acceptable maternal vitamin D (25-hydroxyvitamin FD 25(OH)D) level was considered the first measurement during pregnancy, and if not found, the last reading up to six months prior to pregnancy was considered valid.

A total of 147 pairs (mothers and neonates) were enrolled in this study, of which 18 were excluded because the maternal vitamin D measurement was not valid and 10 were excluded because of neonatal congenital anomalies such as trisomy 21, congenital pulmonary airways malformation, Dandy-Walker malformation, hypoplastic left heart syndrome, and homocystinuria. Furthermore, mothers aged below 18 and above 45 were excluded due to the low number of pregnant women at these ages. Accordingly, 119 neonates were included. The used data were obtained by collecting the medical record number of the included cases (mothers and neonates) through the hospital database (Integrated Clinical Information System [ICIS]). Data were presented as means \pm standard deviation or as median and interquartile range for the continuous variables, where appropriate, after testing the normality. Categorical variables were presented as frequencies and valid percentages. Student's t-test was used to assess the difference in means between fullterm and preterm groups, and chi-square and Fisher's exact tests were used where appropriate. The correlation between maternal Vitamin D and neonatal birth weight was made using Pearson's correlation coefficient. A p-value of $<0.05$ was considered a threshold of significance. The analysis was conducted using SPSS Version 20 (IBM Corp., Armonk, NY, USA). This study was approved by the Institute Ethics Committee in KFSH\&RC.

\section{Results}

The neonates were divided based on the gestational age (Table 1); there were 64 full-term neonates (mean birth weight $=2.54 \mathrm{~kg}$ ) and 55 preterm neonates (mean birth weight $=1.72 \mathrm{~kg}$ ). The mothers' average age was 30.7 years, and there were 104 mothers who had low vitamin D level at one point during pregnancy (87.4\%), with an average vitamin D level of $44.97 \mathrm{nmol} / \mathrm{L}$. For delivery method, 67 neonates were delivered by caesarean section and 52 through spontaneous vaginal delivery. 


\section{Cureus}

\begin{tabular}{|c|c|c|c|}
\hline Measure & Value & Frequency & Percentage \\
\hline \multirow{2}{*}{ Gestational age } & Full-term & 64 & 53.8 \\
\hline & Preterm & 55 & 46.2 \\
\hline \multirow{2}{*}{ Neonatal gender } & Male & 53 & 44.5 \\
\hline & Female & 66 & 55.5 \\
\hline \multirow{2}{*}{ Maternal vitamin D level } & Normal & 15 & 12.6 \\
\hline & Low & 104 & 87.4 \\
\hline \multirow{4}{*}{ Maternal diseases } & Thyroid/parathyroid disorders & 34 & 28.6 \\
\hline & Diabetes mellitus or gestational diabetes & 24 & 20.2 \\
\hline & Hypertension & 7 & 5.9 \\
\hline & Preeclampsia & 2 & 1.7 \\
\hline
\end{tabular}

\section{TABLE 1: Descriptive Information}

After correlating the neonatal birth weight with the maternal vitamin $D$ level during pregnancy, the result was statistically insignificant for both full-term neonates $(p=0.302)$ and preterm neonates $(p=0.736)$. In contrast, comparing the mean maternal vitamin D levels in each neonatal group (Figure 1) showed that fullterm neonates with normal birth weight $(\mathrm{n}=37)$ had a maternal vitamin $\mathrm{D}$ level of $42.46 \mathrm{nmol} / \mathrm{L}(\mathrm{SD} \pm 18.37)$, while full-term neonates with LBW $(\mathrm{n}=27)$ had a maternal vitamin D level of $41.7 \mathrm{nmol} / \mathrm{L}(\mathrm{SD} \pm 22.17)$. Also, preterm neonates with normal birth weight $(\mathrm{n}=30)$ had a maternal vitamin $\mathrm{D}$ level of $54.1 \mathrm{nmol} / \mathrm{L}(\mathrm{SD} \pm$ $27.81)$, while preterm neonates with $\mathrm{LBW}(\mathrm{n}=25)$ had a maternal vitamin D level of $41.28 \mathrm{nmol} / \mathrm{L}(\mathrm{SD} \pm$ 25.41) (Table 2).

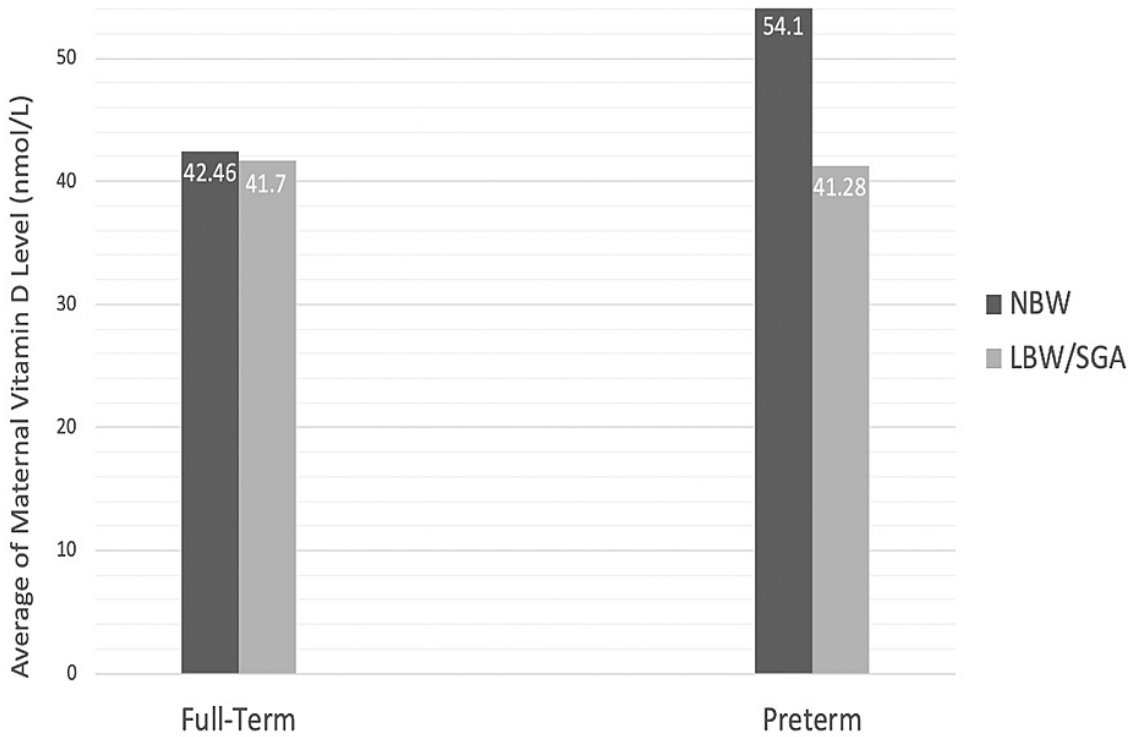

FIGURE 1: Mean Maternal Vitamin D Levels in Full-Term and Preterm Neonates

LBW, low birth weight; NBW, neonatal birth weight; SGA, small for gestational age 


\begin{tabular}{|c|c|c|}
\hline Mean Maternal Vitamin D & Normal Birth Weight & Low Birth Weight \\
\hline Full-term neonates & $42.46 \mathrm{nmol} / \mathrm{L}$ & $41.7 \mathrm{nmol} / \mathrm{L}$ \\
\hline Preterm neonates & $54.1 \mathrm{nmol} / \mathrm{L}$ & $41.28 \mathrm{nmol} / \mathrm{L}$ \\
\hline
\end{tabular}

TABLE 2: Mean Maternal Vitamin D Levels in Full-Term and Preterm Neonates

\section{Discussion}

In this study, maternal vitamin D levels were compared with the neonatal birth weight to establish a correlation between low maternal vitamin D level during pregnancy and LBW in neonates. However, the result showed no correlation between maternal vitamin $\mathrm{D}$ level and neonatal birth weight, which could be related to the fact that $87.4 \%$ of the mothers included in this study had low vitamin D (average vitamin D level $=44.97 \mathrm{nmol} / \mathrm{L}$ ). Despite that, there was a difference in the mean maternal vitamin D levels, which were higher in mothers of neonates with normal birth weight (both full-term and preterm), as shown in Figure 1. Also, a study found that fetal birth weight raised $69 \mathrm{~g}$ per $1 \mathrm{ng} / \mathrm{mL}$ increase in maternal vitamin $\mathrm{D}$ and up to $20 \mathrm{ng} / \mathrm{mL}$. Moreover, the decrease in maternal vitamin D level is associated with an increased risk of unadjusted small for gestational age (SGA) by $19 \%$ and adjusted SGA by $9 \%$ [10]. Multiple studies elaborated on the possible mechanisms of how maternal vitamin D level affects neonatal birth weight:

1) Low maternal vitamin D concentration may lead to suboptimal bone size and density after birth, which leads to LBW neonates [11].

2) Vitamin D has anti-inflammatory effect that regulates placental inflammation by inhibiting decidual NF$\mathrm{KB}$ (nuclear factor kappa B) pathway, which is the main transcription factor of inflammatory mediators. Intrauterine growth restriction (IUGR) can be caused by maternal and placental inflammation, which shows that vitamin D deficiency can increase the risk of inflammation and therefore increase IUGR risk $[9,12]$.

3) There is a relation between vitamin D and insulin-like growth factor (IGF-1) concentration, as vitamin D supplementation increases IGF-1 production in adults [9].

A mother who gets 600 IU daily supplement of vitamin D had increased level of vitamin D in cord and maternal blood and decreased IUGR [13]. Also, an increase in newborn's length with the daily supplement was reported in a randomized controlled trial [14]. But using supplements from mid-pregnancy to six months postpartum did not improve fetal or neonatal growth [15].

Vitamin D has a major role in different fetal growth-related processes including fetal lung development, as it affects the maturation of alveolar type- 2 cells and the epithelial-mesenchymal interactions. Furthermore, maternal vitamin D deficiency increased the risk of developing asthma in boys at the age of six years [16]. A daily dose of vitamin D supplement given to mothers in the second and third trimesters in a randomized controlled trial enhanced broad-spectrum proinflammatory cytokine response of cord blood mononuclear cells to innate and mitogenic stimuli. Also, it showed a 1.7- to 2.1-fold increase in levels of several proinflammatory cytokines (e.g. GM-CSF [granulocyte-macrophage colony-stimulating factor], IFN- $\gamma$ [interferon gamma], interleukin [IL]-1 $\beta$, IL-6, and IL-8) and a four-fold increase in IL-17A production. Therefore, maternal vitamin $\mathrm{D}$ is very important in the development of the fetal immune system, as an adequate level would protect the neonate from asthma-related outcomes including infections [17].

During infancy, vitamin D stores decline by $50 \%$ in less than a month, which causes rapid vitamin D deficiency if no supplements are provided [18]. Therefore, the American Academy of Pediatrics recommends that breastfed and partially breastfed infants be supplemented with $400 \mathrm{IU}$ per day of vitamin D beginning in the first few days of life, as breast milk is not a sufficient source for vitamin D [19].

Vitamin D deficiency in children could cause multiple health issues, such as growth retardation, rickets, increased risk of certain cancers, hypertension, multiple sclerosis, and more severe forms of tuberculosis [20]. Also, growing children with low vitamin D are at a higher risk of developing type 1 diabetes mellitus [21].

\section{Conclusions}

The result of this study showed no correlation between maternal vitamin $\mathrm{D}$ and neonatal birth weight, but mean maternal vitamin D levels were higher in mothers with normal birth weight neonates. Besides, $87.4 \%$ of mothers had low vitamin D levels during their pregnancy, with an average of $44.97 \mathrm{nmol} / \mathrm{L}$. Therefore, further detailed studies on the Saudi population using the data of the primary health care centers across the kingdom are required to establish local guidelines about the treatment of vitamin D deficiency during 


\section{Additional Information Disclosures}

Human subjects: Consent was obtained or waived by all participants in this study. Office of Research Affairs (ORA), King Faisal Specialist Hospital and Research Centre issued approval 2191095. This is a retrospective study which will utilize existing information, with no additional blood test or any other procedure used for purpose of the study. The following other ethical considerations were taken. 1) All data needed for research already exist and were obtained through routine clinical care. 2) All data will be stored in Pediatric Research Unit, accessed only by the Principal Investigator and the assigned Assistant Clinical Research Coordinators. 3) The entire patient's information will be kept strictly confidential. Each patient will be given a study number, and all patient data will be entered in to the designated data sheet (EXCEL) without any patient's identifiers. 4) Waiver of informed consent is submitted with justification. 5) The Declaration of Helsinki and GCP guidelines will be followed. Our approval from Office of Research Affairs (ORA): RAC\# 2191095 . Animal subjects: All authors have confirmed that this study did not involve animal subjects or tissue. Conflicts of interest: In compliance with the ICMJE uniform disclosure form, all authors declare the following: Payment/services info: All authors have declared that no financial support was received from any organization for the submitted work. Financial relationships: All authors have declared that they have no financial relationships at present or within the previous three years with any organizations that might have an interest in the submitted work. Other relationships: All authors have declared that there are no other relationships or activities that could appear to have influenced the submitted work.

\section{References}

1. Adolf Windaus. German chemist. . (2020). Accessed: March 1, 2020: https://www.britannica.com/biography/Adolf-Windaus.

2. Mulligan ML, Felton SK, Riek AE, Bernal-Mizrachi C: Implications of vitamin D deficiency in pregnancy and lactation. Am J Obstet Gynecol. 2010, 202:429.E1-429.E9. 10.1016/j.ajog.2009.09.002

3. Khalessi N, Kalani M, Araghi M, Farahani Z: The relationship between maternal vitamin D deficiency and low birth weight neonates. J Family Reprod Health. 2015, 9:113-7.

4. Martin RJ, Fanaroff AA, Walsh MC: Fanaroff and Martin's Neonatal-Perinatal Medicine. Elsevier, Philadelphia, PA; 2019.

5. Al-Alyani H, Al-Turki HA, Al-Essa ON, Alani FM, Sadat-Ali M: Vitamin D deficiency in Saudi Arabians: a reality or simply hype: a meta-analysis (2008-2015). J Family Community Med. 2018, 25:1-4. 10.4103/jfcm.JFCM_73_17

6. al-Eissa YA, Ba'Aqeel HS, Haque KN: Low birthweight in Riyadh, Saudi Arabia: incidence and risk factors . Ann Trop Paediatr. 1991, 11:75-82. 10.1080/02724936.1991.11747481

7. Haque K: Outcome of low and very low birth weight infants: a case for regionalization of perinatal care in Saudi Arabia. Ann Saudi Med. 1986, 6:247-51. 10.5144/0256-4947.1986.247

8. Momany AM, Kamradt JM, Nikolas MA: A meta-analysis of the association between birth weight and attention deficit hyperactivity disorder. J Abnorm Child Psychol. 2018, 46:1409-26. 10.1007/s10802-0170371-9

9. Chen YH, Fu L, Hao JH, et al.: Maternal vitamin D deficiency during pregnancy elevates the risks of small for gestational age and low birth weight infants in Chinese population. J Clin Endocrinol Metab. 2015, 100:1912-9. 10.1210/jc.2014-4407

10. Wang H, Xiao Y, Zhang L, Gao Q: Maternal early pregnancy vitamin D status in relation to low birth weight and small-for-gestational-age offspring. J Steroid Biochem Mol Biol. 2018, 175:146-50. 10.1016/j.jsbmb.2017.09.010

11. Viljakainen HT, Korhonen T, Hytinantti T, Laitinen EK, Andersson S, Mäkitie O, Lamberg-Allardt C: Maternal vitamin D status affects bone growth in early childhood--a prospective cohort study . Osteoporos Int. 2011, 22:883-91. 10.1007/s00198-010-1499-4

12. Chen Y, Zhu B, Wu X, Li S, Tao F: Association between maternal vitamin D deficiency and small for gestational age: evidence from a meta-analysis of prospective cohort studies. BMJ Open. 2017, 7:016404. 10.1136/bmjopen-2017-016404

13. Tao RX, Meng DH, Li JJ, et al.: Current recommended vitamin D prenatal supplementation and fetal growth: results from the China-Anhui birth cohort study. J Clin Endocrinol Metab. 2018, 103:244-52. 10.1210/jc.2017-00850

14. Asemi Z, Esmaillzadeh A: The effect of multi mineral-vitamin D supplementation on pregnancy outcomes in pregnant women at risk for pre-eclampsia. Int J Prev Med. 2015, 6:62. 10.4103/2008-7802.160975

15. Roth DE, Morris SK, Zlotkin S, et al.: Vitamin D supplementation in pregnancy and lactation and infant growth. N Engl J Med. 2018, 379:535-46. 10.1056/NEJMoa1800927

16. Zosky GR, Hart PH, Whitehouse AJ, et al.: Vitamin D deficiency at 16 to 20 weeks' gestation is associated with impaired lung function and asthma at 6 years of age. Ann Am Thorac Soc. 2014, 11:571-7. 10.1513/AnnalsATS.201312-4230C

17. Hornsby E, Pfeffer PE, Laranjo N, et al.: Vitamin D supplementation during pregnancy: effect on the neonatal immune system in a randomized controlled trial. J Allergy Clin Immunol. 2018, 141:269-278. 10.1016/j.jaci.2017.02.039

18. Vitamin D Supplementation for Infants . (2017). Accessed: August 25, 2020: https://www.who.int/elena/titles/bbc/vitamind_infants/en/.

19. Breastfeeding. (2020). Accessed: August 25, 2020: https://www.cdc.gov/breastfeeding/breastfeeding-special- 


\section{Cureus}

circumstances/diet-and-micronutrients/vitamin-d.html.

20. Holick MF, Chen TC: Vitamin D deficiency: a worldwide problem with health consequences . Am J Clin Nutr. 2008, 87:1080-6. 10.1093/ajcn/87.4.1080S

21. ALkharashi NA: Estimation of vitamin D deficiency prevalence among Saudi children in Armed Forces Hospital and Riyadh Care Hospital in Riyadh, Kingdom of Saudi Arabia and its relation to type 1 diabetes mellitus. Saudi Med J. 2019, 40:1290-3. 10.15537/smj.2019.12.24643 